\title{
PARODY AND THE GAS STATION SEQUENCE IN WILLIAM SHAKESPEARE'S ROMEO AND JULIET
}

Avital Grubstein de Cykman (Avital Gad-Cykman)*

Universidade Federal de Santa Catarina

Florianopolis, Santa Catarina, BR

\begin{abstract}
Baz Luhrmann's 1996 film, William Shakespeare's Romeo and Juliet, is a pop-culture adaptation of the late sixteenthcentury play. The cross-references and transgression of allusions and their postmodern subversive statement along with the extreme intensity with which these elements appear in act one, scene one, and especially in the scene placed at a gas station produce a self-directed irony, a cutting-edge, if playful combination of references that define it as parody in the postmodern sense. Hence, this article examines act one, scene one with a special attention to the gas station sequence, and analyzes it in the light of scholarly definitions of postmodern parody by Linda Hutcheon, John W. Duvall and Douglas Lanier, and of pastiche by Fredric Jameson. Once the hypothesis of parody is established, the article analyzes what the film parodies and in what ways, and what the objective and the impact of the applied humor are.
\end{abstract}

Keywords: Shakespeare; Film Adaptation; Parody; Luhrmann; Postmodernism

\section{Introduction}

Baz Luhrmann's 1996 film, William Shakespeare's Romeo and Juliet, is a pop-styled adaptation of the late sixteenth-century play. The related concept of pop culture, as defined by the Oxford English Dictionary, is read here as "Modern popular culture transmitted via the mass media and aimed particularly at younger people" (WEB). The film displays self-conscious, self-contradictory statements through historical representations lifted out of their initial context and placed in a pop-inspired reality along with cultural allusions to a variety of periods, and transient film genres, elements that constitute a postmodern art endeavor fitting within the definition of postmodernism developed by postmodern philosophers such as Linda Hutcheon. By adapting a historical play with pop culture cinematic tools, Luhrmann offers a new set of references to the public. This type of adaptation is seen with a varied degree of approval. One of the most disapproving theorists is probably Fredric Jameson, who argues in an analysis of historical novels: "we are condemned to seek History by way of our own pop images and simulacra of that history, which itself remains forever out of reach" (25). However, Hutcheon, Douglas Lanier and John Duvall see it in a different manner, or rather, as means to accomplish cultural and social goals.

The director's pop-oriented conception has dictated certain choices such as a soundtrack consisting of music by popular rock bands like Radiohead; mainstream actors like Leonardo DiCaprio and Claire Danes in the leading roles; a made-up world, with visual features from the 1940s, 1970s, and 1990s, an agitated camera and a fast-cutting editing style in the beginning, a reminder of MTV clips and popular film genres. Accordingly, the director says in an interview to the Guardian: 
It's a made-up world comprising twentiethcentury icons ... and these images are there to clarify what's being said, because once you understand it, the power and the beauty of the language works its magic on you. The idea was to find icons that everybody comprehends, that are overtly clear. The hope was that by associating the characters and places with those images the language would be freed from its cage of obscurity. (WEB)

Notably, despite these modern-day expressions, Luhrmann has made minimal modifications in the original text, or rather, in the text as it appears in the Arden edition.

Based on the above, my hypothesis is that the transgression of allusions and their postmodern statement along with the extreme intensity with which these elements appear in act one, scene one, and especially in the scene placed at a gas station (to which I'll refer from now on as the "Gas Station Sequence") produce a self-directed irony, a cutting-edge, though playful combination of references that determine it as parody. Parody subverts the original text by applying to it an interpretation full of color, ado, and speed. It introduces a provocative response to the traditional values accompanying canonical plays and their traditionally rigid production. It also opens room to reconsider pop culture icons, as the appearance implies irony toward simplistic representations. Selfirony and criticism such as the latter is a part of the process of deconstruction explored and developed in postmodern theory.

Hence, the article examines act one, scene one with special attention to the Gas Station Sequence, and analyzes it in the light of scholarly definitions of postmodern parody by Linda Hutcheon, John W. Duvall, and Douglas Lanier, and of pastiche by Fredric Jameson. Once the hypothesis of parody is established, I analyze its subjects, objectives and impact.

\section{A Close Look at Act One, Scene One}

The radical, provocative tone of act one, scene one testifies to Baz Luhrmann's conception of the movie as revealed in his production notes:
Shakespeare's plays touched everyone from the street sweeper to the Queen of England. He was a rambunctious, sexy, violent, entertaining storyteller. We're trying to make this movie rambunctious, sexy, violent and entertaining the way Shakespeare might have if he had been a filmmaker. ... We have not shied away from clashing low comedy with high tragedy, which is the style of the play, for it's the low comedy that allows you to embrace the very high emotions of the tragedy. (The Contemporary Film, notes)

The director has manifested his intention to bridge between the original play and the MTV generation, or, as Peter Travers comments in Rolling Stone, to "make Romeo and Juliet accessible to the elusive Gen-X audience without leaving the play bowdlerized and broken" (qtd. in Brode 56). With this goal in mind, the director sets out to surprise and hook the viewers with choices taken from their own culture.

A TV set with changing channels constitutes the first image of the film. An anchorwoman appears and transmits the prologue as a news bulletin. She reports on the deaths of Romeo and Juliet, as the note "Star Crossed Lovers" rises on the screen behind her. The camera moves to a broken wedding ring, with the inscribed words "I love thee," followed by headlines from the newspaper Verona Today, headshots and names of the leading characters, and the image of two overpowering skyscrapers, bearing the names Montague and Capulet.

As soon as the movie begins, it becomes clear that it is not a traditional version of Romeo and Juliet, but a rather provocative one. The director ironically abuses the conventions regarding the Elizabethan way by which he could have tackled Romeo and Juliet, and the genre of film that is traditionally tending toward a historical production. This process of misappropriation of historical representations plays with expectations and conventions, and cracks the well-known historyculture construction of canonical works.

The surprise evokes a smile, a reaction the director welcomes, as he clarifies in an interview with Geoff Andrew from the Guardian: "Could we ever get past that cerebral cool and perceived cool? It requires this idea of comic tragedy. Could you make those switches? Fine in Shakespeare - low comedy and then 
you die in five minutes." He adds a glance behind the screen,

So we thought, let's look back to a cinematic language where the audience participated in the form. Where they were aware at all times that they were watching a movie, and that they should be active in their experience and not passive. Not being put into a sort of sleep state and made to believe through a set of constructs that they are watching a real-life story through a key-hole. (1)

With the line "Where civil blood makes civil hands unclean," the film changes in style, displaying fast-cut camera shots that are common in action movies. The changed scene opens with a speeding dark sedan, its windows tinted gold, almost running into a pickup truck on Verona Beach highway. The following line from the original transcript illustrates the similarity to action movie: "Like thunderous, jousting opponents, the cars pass in a deafening cacophony of noise." The camera follows the fast-changing movements as instructed in the transcript: "Cut to, tight on, wide shot, tight on, close on” (WEB).

Next, Gregory and Sampson, the truck's driver and his companion, divide a frame, laughing, just before the irritated face of the sedan driver, the red-haired Benvolio, appears. The truck turns sharply, screeching, into a busy driveway of a gas station, where the camera closes on the boasting Gregory and Sampson, and the disgusted Benvolio, who is driving the approaching sedan. The camera cuts to Tybalt's shiny black boots, decorated with tiny, silver, cat-shaped spurs, as he plants them on the ground like a western-film-hero. The focus moves to other feet, belonging to the toughlooking Latin youth, ABRA and the "goatee" Petruchio.

A series of close ups shows the tense facial expressions of boys from both groups, followed by shots of a rearview mirror, and of Sampson biting his thumb. The sedan reverses in full speed and blocks the truck, as a panicked mother and her children scurry away. Benvolio's cowboy boots appear, a toilet is flushed, and he comes out of the lavatory. Now, a tense dialogue arises between the Montague Boys whose name is shown, tattooed on a shaven head, and the Capulet Boys, ending with the line, "Draw if you be men," and hands reaching for guns. The camera zooms on Benvolio's engraved gun's name, "sword," then moves to the dark cold eyes and feline smile of Tybalt. With a cigarette clenched between his teeth, Tybalt points a pistol at Benvolio. The conflict escalates into a battle.

Critic Richard Gyde from Shakespeare Online describes it well:

The occasional slow-motion shot makes their
moves seem balletic (a reference, perhaps,
to West Side Story?) as well as exaggerating
the suspense in key moments. The fight itself
is impossible: a pastiche of all the devices of
acting and editing we expect from such scenes:
the echoing ricochet bullet, the instant over-
the-shoulder shooting, the commando roll,
the innocent bystanders who get in the way
but narrowly escape to safety, the slam-zoom
extreme close-ups, the slow tracking of an
opponent viewed through the cross-bars of the
telescopic sight. (WEB)

The scene ends with fire and mayhem. This episode illustrates Luhrmann's strategy to attract the public with familiar concepts, styles and symbols, and provoke an interest that would last until the end of the movie.

Luhrmann comments on the scene in the aforementioned interview for the Guardian:

OK. They're at a gas station. They've got guns. That's a bit weird. What if we dealt with it like a spaghetti western? You get close ups and you get the language vernacular of that. By the time you get to Romeo and Juliet in the love scene, it's pretty much a bit Zeffirelli, it's very romantic, even if you don't know that, you understand very quickly what kind of cinematic form you are in, subconsciously. The idea of that is to help the very fast gear changes you need to do. (2)

Examining the sequence based upon Linda Hutcheon's definition of parody raises the assumption that Luhrmann legitimizes the pop style of the film by taking it to an extreme end, subverting it, and then, once the public absorbs it, slowing it down. This paradoxical approach creates a certain estrangement and critical 
distance much in the way the above mentioned Jameson's quote illustrates it, but then undoes it. Afterwards, the director begins slowing and mellowing the style, opening space for romance. Due to the change in style toward the next sequence of the movie, the sense of postmodern ambiguity, found in the contradiction of poetic lines and Western movies, for example, rises and then weakens once the lovers meet. In fact, the Gas Station Sequence is the one part of the film to which the definitions of parody apply rather fully. However, Jameson would have most likely defined this part as pastiche, and would have been convincing enough, thanks to the exhilarating mess of styles and genres, symbols and images. Notwithstanding, the components of parody mentioned by the other discussed theorists weigh in the analysis differently.

The following examination is based on the film, the transcript, scholars' analyses, and the director's and critics' words. Firstly, I will lay down a necessary if short overview of the definitions of parody.

\section{Parody}

There is a historical and substantial connection between the roots of parody and the current meanings of the term. Beginning with Greek literature, the term "parody" referred to a poem that imitated another, representing men as a morally lower type for the sake of a comic effect. At the time, Aristotle crowned the poet and playwright Thasian as the inventor of parodies (ii, 5). $\mathrm{He}$ also pointed out that morally "lowering" imitations existed in dancing, flute-playing, lyre-playing, and language, whether prose or verse unaccompanied by music" (ii, 3-4). For the scope of this article, I will extend his inclusion of the existent forms of arts of his days to all the forms of arts in current days.

Until the eighteenth century, parodies imitated a serious and even heroic style in order to mock and ridicule. According to Ian Johnston, in 1693, John Dryden defined the type of parody that is now known as "mock heroic," a form of burlesque, which sets a disproportionate and witty distance between the elevated language and the foolish, heroic pretensions of trivial people (WEB).
Back to history, the following change in the definition of parody came from Jonathan Swift and provoked a scholarly debate regarding its meaning. In A Tale of a Tub Swift writes that a parody is an imitation of an author one wishes to expose. Interestingly, Swift used Dryden's style in the utilization of foreign words, so there is a possibility that his words exposed and mocked Dryden. Either way, his definition changed the popular concept of parody to any comic imitation aspiring to expose and ridicule.

Fundamentally, imitation has remained the common element in parody from 350 B.C.E to our days. Yet, the requirement of ridicule, belittling, and satirizing in regard to the imitated object, style, author, genre, values or the artist's own work has been put into question by postmodern scholars. Hutcheon, for instance, claims that in this postmodern age, parodies are never made to ridicule what they imitate. They introduce a transgression of elements from different periods and cultures for the sake of play and not in order to criticize. Still, she indicates that parodies can make a social criticism of representations, and cites the painter Burgin to demonstrate it. According to him, the parody created by lifting classic art out of its original context of art history aids in throwing off the dead end of art history and its belief in eternal values while still maintaining the richness and density of the original (103). Hutcheon adds that postmodern parody does not try to offer dialectic resolution or recuperative evasion of contradiction in narrative fiction, photography, or film (107).

Notably, Jameson applies the term "pastiche" to the same sets of references and imitations that Hutcheon defines as parody. Basically, Jameson denies the existence of parody in postmodern artistic expressions, since, in his opinion, the imitations lack intertextuality, self-reflexivity, political or historical content or humor. In reply to Jameson, Hutcheon distinguishes between parody and pastiche, and argues that the duplicity of politics of authorized transgression, necessary in parody, remains intact. John Duvall, who has studied the theories of both, sees the origin of the differences in the disciplines from which the scholars elaborated their theories. Jameson's postmodernism focuses on the consumer, while Hutcheon's originates with the 
artist as producer. Beyond Hutcheon's good reasoning, this explanation renders her definition suitable for the following analysis of the film.

\section{Analysis}

Within this theoretical frame, focusing on Hutcheon's definition and with regard to Duvall's and Lanier's, the self-referential, self-reflexive and ambiguous juxtaposition of historical and cultural references, location, periods, and styles in act one, scene one constitutes parody. Certain components of Hutcheon's conceptualization of parody are more present than others, depending on the scene. The TV sequence, for instance, parades a large range of pop allusions that result in a comic effect. However, it does not contain a genre transgression, or rather a crossreference between genres, the way the Gas Station Sequence does.

As for the more traditional form of parodymocking, mocking the protagonists, especially Romeo and Juliet, is far from Luhrmann's or his scriptwriting partner Craig Pearce's conception. As seen earlier, the director has proclaimed his intent to transfer the characters to current days without changing their characteristics. However, the Gas Station Sequence stretches this intention to its limit, since the symbols of Western and Action movies add irony and distance from the exquisite language.

When the comic effect seems more powerful than other variables of parody, the work raises scholarly brows such as Jameson's. Furthermore, even when an adaptation includes cross-cultural references, generating a comic effect, the agreement to what extent the adaptation is parody is still put into question. For instance, playwright Scott Eckert's refers to his modern version of Hamlet and rejects its definition as parody despite the cross-cultural pop references. He argues that his modernized version of Hamlet is a "comic deconstruction, which presents Shakespeare to modern audiences in terms that are entertaining and relevant while preserving the integrity of the original" (176). A part of the controversy, I will briefly observe, is the question of what constitutes an original text, what is the meaning of integrity in relation to adaptation of historical texts, and whether postmodern parody can be seen seriously. In response to the latter, an intention to adapt Shakespearean plays for current audiences does not interfere with the definition or presence of parody. It is rather irrelevant, in fact. Parody does not mean sulking disrespectfully (usually), as it does not (necessarily) mock the adapted text or work. Parody acts through irony and provocation, without disqualifying (completely) its cultural references. Parody may raise questions, doubts and/or laughs, while attributing characteristics and constructing new meanings. In fact, Luhrmann's and Pearce's production notes testify to a similar intention of revival, and yet certain parts of their movie qualify as parody, as this article demonstrates.

In addition, the "Shakespearean angle" is important to the analysis as well. Richard Lanier studies the hypothesis of parody in response to Eckert, relying on the play itself and not on its conceiver's view. He claims that there are reasons to place Eckert's modern Hamlet within the tradition of Shakespeare parody stretching back into Victorian Shakespeare burlesques, where "high" Shakespeare was transported into the "low" contexts of characters, language and popular tunes (177). In this sense, too, Luhrmann's film exhibits parodic characteristics, with the exception of its loyalty to the "high" language, the poetic style so strange to pop culture. As a result, the lack of correlation between the Shakespearean language and the people of Verona Beach provokes a comic effect and constitutes parody.

Notably, the whole act may be considered parody according to the postmodern concept introduced by Hutcheon, but the Gas Station Sequence displays more variables of postmodern parody than the rest of the act. Beyond the above mentioned components, the crossreference and cross-genre are speedy and surprising. In an adamant argument, Duvall states that if the narrative stays within the same genre, literary or filmic history, it is not parody. Hutcheon, on her part, does not include a cross-genre among the basic constructs of parody, but she acknowledges in her analysis of parody and postmodernism that crisscross representations inscribe and subvert dominant ideologies. Either way, the Gas Station Sequence and the film as a whole display 
much of cross-genre. Scriptwriter Pearce describes it: "Stylistically it changes very dramatically, echoing recognizable film genres. We've taken identifiable film styles so part of it looks like 'Rebel without a Cause,' part of it looks like a 'Busby Berkeley' musical and another part of it looks like a Clint Eastwood 'Dirty Harry' pictures" (WEB).

In this regard, it should also be noted that, according to Duvall, mere historiographic metafiction does not constitute postmodern parody since it lacks the impossibility of impacting the public. Only a very limited number of viewers are able to perceive such references. He also mentions that this is a determiner according to Fredric Jameson (13). Hutcheon, too, rejects the inclusion of sophisticated references in parody, emphasizing the necessity of transparence and effect. She writes, "there exists a very real threat of elitism or lack of access in the use of parody in any art. This question of accessibility is undeniably part of the politics of postmodern representation. But it is the complicity of postmodern parody - its inscribing as well as undermining of that which it parodies - that is central to its ability to be understood" (106). This variable appears to contradict, or at least limit, her inclusive definition of parody. Furthermore, accessibility is a quality that does not depend on the film itself but on time and place and other contextual ever-changing factors within a film's long life. It demands a definition of what is elitist in each point of time and every location the film goes through, an extremely transitory and limiting classification of parody. However, the Gas Station Sequence includes such a rich variety of genres and cultural references, and so many allusions to popular culture at the time the film comes out, that the concept of historiographic metafiction is hardly wide enough to define it.

Other elements of parody listed by Richard Lanier apply to the Gas Station Sequence as well: the crossreferences target a specific cinematic popularization of Shakespeare, or rather the MTV public or the X generation; the act contains dark violent tone forms of symbolic counter-violence in the ruthless behavior, and especially in the battle; it problematizes cinematic Shakespearean pop films' hybridity even as it engages in it, since it creates a knowing, distant viewer; and lastly, the scene of parody is embedded in an otherwise mostly serious film.

\section{What This Parody Parodies}

After establishing the presence of parody, the question what the sequence is parodying is not easily answered, despite the sense of wild disruption between traditional productions and this one, with its pop treatment of postmodern fluidity and ambivalence, pattern-breaking attitudes and humorous effect. In this case, turning to the questions Lanier introduces in relation to contemporary Shakespearean parodies helps determine the object of parody in the Gas Station Sequence and beyond.

For instance, Lanier suggests checking whether the parody mocks the possibility of pop culture to tackle a play by Shakespeare (177). Indeed, self-reflexivity is such an integral part of parody that the maddening speed in which symbols and genres are explored makes fun of it, while at the same time attract audiences to the Shakespearean work and to the wild ride. However, the question can also be taken as mere preoccupation with quality. Critic Michael Anderegg, for example, writes, “Baz Luhrmann's William Shakespeare's Romeo + Juliet could be mistaken for yet another (mis) appropriation of Shakespeare's play for purposes of parody or even burlesque, a hip (hop?) retelling aimed at an irredeemably low-brow audience of clueless teenagers inhabiting an intellectually bankrupt culture" (72). Clearly, Anderegg rejects the notion of parody as defined by postmodern theorists as if parody cannot be in itself a worthy social, cultural, and historical artistic tool. In relation to his own question regarding quality, he concludes that the film defies a low-brow reading thanks to Shakespeare's "richly poetic language" and Luhrmann's own style, which often reflects his experience in theater and opera and evokes historical avant-garde cinematography. He claims that Luhrmann produced a contemporary cultural object that aids in reviving Shakespeare's works at present (72-3). ${ }^{1}$ 
The production notes testify indeed to the production's attempt to be part of the revival of Shakespeare's work, or rather, the "actualization" of it. The director's use of parody, however, does not contradict it. Instead of standing in reverence, the production echoes films like Dirty Harry and Rebel Without a Cause in order to convey Shakespeare's greatness. Accordingly, Luhrmann says in an interview for "In the Director's Chair" that he is "mad about Shakespeare" and is inspired by him. He goes on to describe Shakespeare as a "mad pie" who stole the plot but wrote an inspiring play worthy of preservation and production (WEB).

The question whether parody may have an impact is introduced by Lanier as well. He asks: "Is the parody's effect finally transgressive, a popular riposte to a dominant voice of traditional high culture? Or is it in fact conservative, a humorous finally selfconsuming demonstration of the folly of popularizing Shakespeare?" Or, most provocatively: "does the parody target both Shakespeare and Shakespop at the same time (though not in the same way), leaving the viewer in a position of superiority to both?" (177).

It is possible to read Luhrmann's parody, much like pop culture, as mere play. The embedded self-irony, and the somewhat self-congratulatory wink in the sequence can be taken as elements of play. Alas, this is not an easily dismissible hypothesis, especially when referring to Jameson's theory that the so-called parody is pastiche or mere play without any profound implications. While disappointing, in comparison to other answers to what the sequence means or what it parodies, the play opens other possibilities Jameson defies. Hutcheon, unlike him, defends the playful side of parody, seeing that it never ends in itself. In fact, she attributes to parody social criticism, although she may be "plucking the teeth" of her own statement, arguing that postmodern ambiguity leads to the lack of a definite resolution. Either way, she argues it can "Bring out the politics of representation by baring and thus challenging convention" (107).

In this sense, Luhrmann's play goes beyond fun to subversion. The extreme speed, loud sounds, and high colors, and the pop-style characters contradict in such a degree the traditional treatment of the play and the poetic language, they hint at an over-ecstatic play with pop symbols and, simultaneously, show the weakening centers of power of the past. By doing so, they transform into a provocation against the film's sources of references. In this vein, the violence and gang fighting, an imitation of overly-staged violence in other genres and TV clips, create a distance that allows the viewer to identify the ridicule in expressions of violence. More irony is directed toward historical representations of the religious order, set so far from their original context they are exposed in their outdated doctrine. There is undeniable social criticism where overpowering religious icons are set in an extremely violent modern city.

\section{Conclusion}

This article has analyzed and sustained the presence and the effect of parody in William Shakespeare's Romeo and Juliet, act one, scene one, emphasizing the Gas Station Sequence. The overview of the term has clarified that an act of imitation has been a required element throughout history. Other variables of parody have been added or omitted, especially in postmodern parody definitions, according to which this postmodern film is best understood. However, the elements of play, subversion, exposure, and social criticism go hand in hand with postmodernism, and are parts of parody.

The analysis has also established that act one, scene one was not only made to play or attract viewers with superficial images but to question and provoke the history-culture context of the Shakespearean play, the traditional way of production, and pop culture in its transgression of elements. Traditional elements are questioned as they appear against a backdrop of current symbols and dynamics. The irony of the juxtaposition creates a critical space of observation, favoring socio-historical processes of deconstruction. As lowbrowed clichés and symbols surface, in an astounding contradiction with past attitudes, everything explored here is set for a new examination.

In the light of these accomplished objectives, the self-absorbed playful effect condemned by Jameson takes a back seat at most. Parody in the Gas Station 
Sequence and beyond plays important cultural roles, echoed in Hutcheon's words:

Perhaps parody is a particularly apt representational strategy for postmodernism, a strategy once described (Said 1983: 135) as the use of parallel script rather than original inscription. Were we to heed the implications of such a model, we might have to reconsider the operations by which we both create and give meaning to our culture through representation. And that is not bad for a so-called nostalgic escapist tendency. (117)

Hands down, as a pop style author might have articulated it, the parody in William Shakespeare's Romeo and Juliet is rich.

\section{Note}

1. Intriguingly, two pop-cultured Shakespeare movies that followed this production, 10 Things I Hate About You (1999,) an adaptation of The Taming of the Shrew, and $O(2001$,$) an adaptation of Othello, are very loosely$ based on the Shakespearean plot, and do not repeat the utilization of the original text. Further analysis could investigate whether Luhrmann's production and the questions accompanying it have inspired a deeper dive into pop culture and a greater distance from the Shakespearean play.

\section{References}

10 Things I Hate About You. Dir. Gil Junger. Perf. Joseph Gordon Levitt, Heath Ledger, Julia Stiles. Touchstone Pictures, Mad Chance Jaret Entertainment. 1999.

Anderegg, Michael. "Cinematic Shakespeare". Lanham, MD: Rowman \& Littlefield Publishers. 2003. Web. 9 November 2016.

“James Dean Meets the Pirate's Daughter: Passion and Parody in William Shakespeare's Romeo and Juliet and Shakespeare in Love." Shakespeare, the Movie, II: Popularizing the Plays on Film, TV, Video, and DVD. Ed. Richard Burt and Lynda E. Boose. London: Routledge, 2003. Web. 9 November 2016. p. 56-71.

Andrew, Geoff. "Guardian Interviews at the BFI," Guardian. 7, Sep 2001 Web. 9 November 2016.

Aristotle. Poetics, trans. S. H. Butcher, (Greece: 350 B.C.E) ii. 5. Web. 9 November 2016.

Brode, Douglas. Shakespeare in the Movies: From the Silent Era to Today. New York: Berkley, 2001.
Duvall, John W. Ed. Productive Postmodernism. Consuming Histories and Cultural Studies. Albany: University of New York Press, 2002.

Eckert, Scott. "Shakespeare for the Modern Man, Lesson 2: Hamlet (2003)" In: Douglas Lanier, "Will of the People: Recent Shakespeare Film Parody and the Politics of Popularization." A Concise Companion to Shakespeare on Screen, ed. Diana E. Henderson. Malden, MA: $\quad$ Blackwell, 2006.

Fredric, Jameson. Postmodernism, or, the Cultural Logic of Late Capitalism. Durham: Duke UP, 1991.

Gyde, Richard. "Baz Luhrman's William Shakespeare's Romeo and Juliet - a Review." Web. 9

November 2016.

Hutcheon, Linda. The Politics of Postmodernism. London $\&$ New York: Routledge, 1989.

Johnston, Ian. "A Brief Introduction to Restoration and Eighteenth Century Satire." Lecture. Malaspina University, Vancouver Island University, Vancouver, 1998. Web. $9 \quad$ November 2016.

Lanier, Douglas. "Will of the People: Recent Shakespeare Film Parody and the Politics of Popularization." A Concise Companion to Shakespeare on Screen. Ed. Diana E. Henderson. Malden, MA: Blackwell, 2006. p.176-196.

Luhrmann, Baz. "In the Director's Chair, Jason Solomon's interviews". Guardian, 2009. Web. 9

November 2016.

Interview with Geoff Andrew. Guardian. 7 Sep 2001. Web. 9 November 2016.

O. Dir. Tim Blake Nelson. Perf. Mekhi Phifer, Josh Hartnett, Andrew Keegan, Julia Stiles. Chickie the Cop, Daniel Fried Productions, 2001

"Pop Culture, n." OED Online. Oxford University Press, September 2016. Web. 9 November 2016.

Pearce, Craig. William Shakespeare's Romeo and Juliet original transcript, 1996. Web. 9 November 2016.

Production notes. Twentieth Century Fox 1996. Web. 9 November 2016.

Shakespeare, William, Baz Luhrmann, Craig Pearce, and John Bettenbender. The Contemporary Film - The Classic Play - Romeo \& Juliet. New York: Bantam Doubleday Dell, 1996.

Shakespeare, William. "Romeo and Juliet." The Arden edition of the works of William Shakespeare. Ed. Brian Gibbons. London: Routledge (1996 ed.) 
Solomon, Jason. "Interview in the Director's Chair," Guardian, 2009. Web. 9 November 2016.

Swift, Jonathan. A Tale of a Tub and Other Works. London, 1704. Cambridge: Cambridge University Press, (2010 ed.)

William Shakespeare's Romeo and Juliet. Dir. Baz Luhrmann. Perf. Leonardo DiCaprio, Claire Danes, Paul Sorvino. Twentieth Century Fox, 1996.

Recebido em: 14/07/2016

Aceito em: 09/11/2016 